Article

\title{
Assessment of Different Channel Equalization Algorithms for a Converged OFDM-Based 5G mm-wave A-RoF System at $60 \mathrm{GHz}^{\dagger}$
}

\author{
Umar Farooq (D) and Amalia Miliou *(D)
}

check for updates

Citation: Farooq, U.; Miliou, A.

Assessment of Different Channel Equalization Algorithms for a Converged OFDM-Based 5G mm-wave A-RoF System at $60 \mathrm{GHz}$ Appl. Sci. 2022, 12, 1511.

https://doi.org/10.3390/ app12031511

Academic Editor:

Rodolfo Dufo-López

Received: 16 December 2021

Accepted: 26 January 2022

Published: 30 January 2022

Publisher's Note: MDPI stays neutral with regard to jurisdictional claims in published maps and institutional affiliations.

Copyright: (C) 2022 by the authors. Licensee MDPI, Basel, Switzerland. This article is an open access article distributed under the terms and conditions of the Creative Commons Attribution (CC BY) license (https:// creativecommons.org/licenses/by/ $4.0 /)$.
Center for Interdisciplinary Research and Innovation, Department of Informatics,

Aristotle University of Thessaloniki, 54124 Thessaloniki, Greece; umfarooq@csd.auth.gr

* Correspondence: amiliou@csd.auth.gr

+ This paper is an extended version of paper published in 2021 IEEE 11th Annual Computing and Communication Workshop and Conference (CCWC) held in Nevada, USA, 27-30 January 2021.

\begin{abstract}
In this article, we simulate a converged 5G mm-wave analogue radio-over-fiber (A-RoF) system at $60 \mathrm{GHz}$, and perform offline signal processing to equalize the dispersive optical link with the three most frequently employed algorithms, i.e., the simple least mean square (LMS) algorithm, the constant modulus algorithm (CMA) and the adaptive median filtering (AMF), which are implemented in Matlab. The performances of the different algorithms are compared for various optical fiber lengths with respect to the EVM values obtained before and after equalization. In the case of QPSK in OFDM subcarriers, it is observed that the CMA algorithm performs better than the LMS and MF algorithms, with 2\% and 1.4\% EVM improvement respectively, while for 16QAM in OFDM subcarriers it is observed that the LMS algorithm has a very small improvement of $0.2 \%$ EVM compared to the MF algorithm, while CMA is not suitable for 16QAM modulation in the proposed converged 5G mm-wave A-RoF system at $60 \mathrm{GHz}$.
\end{abstract}

Keywords: analogue radio-over-fiber; least mean square; constant modulus algorithm; median filtering algorithm; mm-waves; orthogonal frequency division multiplexing

\section{Introduction}

5G's areas of application are diverse and innovative, whether delivering a 3D video, mission critical communications like healthcare, or massive machine-type communications (IoT). At the same time, optical networks have massively expanded in order to manage the constantly growing communication requirements which play a prominent role in the shaping of the evolution of beyond-5G and $-6 \mathrm{G}$ mobile networks due to the extreme bandwidth, low latency, accurate synchronization, and coverage requirements imposed by 3GPP [1-3] carrying traffic to and from 5G small cells. In mobile fronthaul, the cloud radio access network (C-RAN) advocates for the separation of the centralized baseband units (BBUs) of all base stations (BSs) from the remote radio heads (RRHs), placing them in a centralized location or even virtualizing them in the cloud, in an effort to reduce the power consumption and cost of the support equipment. In order to cater the enormous bandwidth, high throughput and adaptable access demands in the next-generation access networks, the hybrid fiber-wireless access network is cropping up as a propitious access network architecture which can deliver both wired and wireless access. Common Public Radio Interface (CPRI) is the protocol primarily employed in the fronthaul links between BBUs and RRHs. CPRI is a digital communication specification of quantized waveforms of baseband signals used in digital radio-over-fiber (D-RoF). However, CPRI demands an extremely high bandwidth, especially for MIMO applications due to the digitization process [4], raising serious concerns regarding the spectral efficiency of the digital optical fronthaul. Furthermore, enhanced CPRI (e-CPRI) - although it requires more 
complex RRHs-has widely mitigated the situation by fostering higher-layer functional splits, relaxing the inappeasable throughput provision of the transport network [5]. As a consequence, analog radio-over-fiber (A-RoF) provides a solution which exploits the bandwidth utilization efficiency while providing high-capacity and flexible fronthauling. Moreover, the unlicensed $60 \mathrm{GHz} \mathrm{mm}$-wave band has gained notable prominence due to the worldwide license-free spectrum of 7-9 GHz [6]; the converged mm-wave band at $60 \mathrm{GHz}$ with optical fiber networks delivers a high expanse, flexibility, wider coverage, and energy efficiency for high throughput [7] signal transmission in access networks. However, such a converged network is affected by chromatic dispersion in the standard single mode fiber (SSMF). Narrowband transmitters can be used for throughput up to $2.5 \mathrm{Gbit} / \mathrm{s}$ in order to solve dispersion-related problems. Dispersion limits the communication distance for high-throughput (>10 Gbit/s) systems such as Orthogonal Frequency Division Multiplexing (OFDM). Hence, it is important to compensate chromatic dispersion in the optical fiber, as it degrades the resulting electrical output. In order to compensate for such an impediment, the authors in [8] proposed an optical single-sideband (SSB) modulation scheme-called "collateral electro-optic modulation"—by using parallel electro-optic phase and intensity modulators. In [9], an approach to reduce the dispersion over a SMF channel consisting of mode-locked lasers for mm-waves' creation and transmission was proposed. A dispersion compensation fiber (DCF) to eliminate dispersion in an unlicensed band RoF channel with a $40 \mathrm{~Gb} / \mathrm{s}$ data rate employing Quadrature Phase Shift Keying (QPSK) modulation in OFDM was proposed in [10], while in [11] the authors proposed a V-band mm-wave frequency of 57-66 GHz using field programming gate arrays (FPGAs) to restore the transmitted signal in a converged OFDM-RoF real-time reception system. A dispersion-shifted fiber (DSF) was used in [12], but this approach is not suitable with 5G standards. Another approach is to use a $1310 \mathrm{~nm}$ instead of a $1550 \mathrm{~nm}$ wavelength lasing frequency because of its near-zero chromatic dispersion value, but it has higher optical loss. In [13], the authors proposed a $25 \mathrm{GHz}$ mm-wave over an SSMF system using OFDM which comprises a dual-wavelength source and $20 \mathrm{~km}$ of SSMF link, and the authors investigated the nonlinearities related to the MZM (Mach-Zehnder Modulator), amplifier and various other noise sources. In [14], a spurious-free dynamic range (SFDR) amplification strategy based on single side band (SSB) phase modulation was proposed and experimentally demonstrated. The polarization states entering into the phase modulator and the polarizer would eliminate the dispersion and nonlinearity of the modulation used. Three different linearization technologies for RoF transmiss $\backslash$ outpresented and compared in [15]. For RoF transmission, a baseband digital linearization technique without any digital-to-analog converter (DAC) and analog-to-digital converter (ADC) may be propitious. In [16], the authors designed a specific cascaded LMS equalizer for a $60 \mathrm{GHz}$ mm-wave RoF system, and the experimental results showed the transmission of a 5 Gbps binary phase shift keying (BPSK) signal for $10 \mathrm{~km}$ of SSMF and a $1.5 \mathrm{~m}$ wireless link. A cost-effective RoF network consisting of 850-nm Single Mode Vertical Cavity Surface Emitting Lasers (VCSEL) and SSMF was proposed in [17], achieving a data throughput of $134.4 \mathrm{Mbit} / \mathrm{s}$ up to a distance of $1.5 \mathrm{~km}$ using the 256QAM modulation format. The authors in [18] presented the transmission of a $20 \mathrm{MHz}$ long-term evolution (LTE) signal over a $70 \mathrm{Km}$ SSMF link for wireless signal transmission with a 64QAM modulation format, and the performance was compared with a conventional A-RoF system. Siming Liu et al., in [19], experimentally demonstrated a variable step size LMS equalizer in a $60 \mathrm{GHz}$ RoF system with a data rate of $5 \mathrm{Gbit} / \mathrm{s}$ employing a BPSK modulation scheme. Moreover, a digital predistortion (DPD) technique on RoF links consisting of VCSEL and SSMF for LTE scenarios was used in [20]. The performance of the DPD was measured from varying input power levels, while in [21] a neural network (NN)-based DPD technique was demonstrated in order to overcome the signal impairments and nonlinearitiesin A-RoF systems. In [22], a modified constant modulus algorithm (MCMA) was introduced in order to minimize the absolute difference between the generalized function of the equalizer output and the source symbols; in [23], a joint equalization algorithm which consisted of the Decision-Directed Least Mean Square 
(DD-LMS) and Modified Constant Modulus Algorithms (MCMA) was used to provide Inter-Symbol-Interference (ISI) at the receiving end. Finally, in [24], a blind nonlinear compensator was employed, which was ingrained in the constant modulus algorithm for the compensation distance of $4000 \mathrm{~km}$ using erbium-doped fiber amplifiers (EDFAs) after every fiber span of $50 \mathrm{~km}$. The techniques suggested above to neutralize dispersion mostly consisted of expensive equipment, which increased the total system budget and intricacy, and the employed algorithms were complex. In this research work, we design a converged $5 \mathrm{G} \mathrm{mm}$-wave $60 \mathrm{GHz}$ A-RoF system in a popular commercial VPI Photonics Transmission Design Suite ${ }^{\mathrm{TM}}$ [25], employing OFDM with QPSK and 16QAM in the subcarriers. Table 1 gives the different methods discussed in the literature review in order to provide the dispersion and nonlinearities in converged mm-wave OFDM A-RoF systems. Although higher-order modulation formats could provide a higher bandwidth, they reduce the robustness of the system because the data is more sensitive to noise and interference, as the receiver must accurately detect more distinct phases and amplitudes with very small differences [26]. The transmission link in this proposed simulation consists of an SSMF with $17 \mathrm{ps} / \mathrm{nm} / \mathrm{km}$ dispersion. In order to compensate for the channel-dispersive properties, Digital Signal Processing (DSP) is carried out in Matlab [27]. Equalization in the form of the least mean square algorithm [28] and simple adaptive median filter algorithm (AMF) is applied for the 16QAM modulation format, while a constant modulus algorithm [29] is utilized for QPSK modulation for the OFDM subcarriers.

Table 1. Methods discussed in the literature review to compensate for the dispersion in converged mm-wave OFDM A-RoF systems.

\begin{tabular}{|c|c|c|c|}
\hline Literature Review & $\begin{array}{c}\text { Approach/Methods } \\
\text { Discussed }\end{array}$ & Pros & Cons \\
\hline [8] & $\begin{array}{c}\text { Used parallel } \\
\text { electro-optic } \\
\text { modulation by using } \\
\text { parallel electro-optic } \\
\text { phase and } \\
\text { intensity modulators }\end{array}$ & $\begin{array}{l}\text { Suitable for long } \\
\text { reach RoF links }\end{array}$ & $\begin{array}{c}\text { Required } \\
\text { costly hardware }\end{array}$ \\
\hline [9] & $\begin{array}{l}\text { Mode-locked lasers } \\
\text { for mm-waves } \\
\text { generation combined } \\
\text { with } \\
\text { MZM interferometer }\end{array}$ & $\begin{array}{c}\text { Applicable to any } \\
\text { RoF system for } \\
\text { mm-wave generation }\end{array}$ & $\begin{array}{c}\text { Required } \\
\text { costly hardware }\end{array}$ \\
\hline$[10,12]$ & $\begin{array}{c}\text { A dispersion } \\
\text { compensation and } \\
\text { dispersion shifted } \\
\text { fiber is used }\end{array}$ & Easy to use & $\begin{array}{l}\text { Old method and } \\
\text { costly fiber }\end{array}$ \\
\hline [11] & $\begin{array}{l}\text { Use field } \\
\text { programming gate } \\
\text { arrays (FPGAs) to } \\
\text { restore the } \\
\text { transmitted signal }\end{array}$ & $\begin{array}{l}\mathrm{V} \text { band /W band } \\
\text { OFDM RoF system }\end{array}$ & $\begin{array}{c}\text { Required costly and } \\
\text { more power } \\
\text { hungry hardware }\end{array}$ \\
\hline [13] & $\begin{array}{c}25 \text { GHz mm-wave } \\
\text { over SSMF system } \\
\text { using OFDM which } \\
\text { uses a dual } \\
\text { wavelength source }\end{array}$ & $\begin{array}{l}\text { Dual wavelength } \\
\text { modulation and } \\
\text { single modulation } \\
\text { techniques are used }\end{array}$ & $\begin{array}{c}\text { Uses } 25 \mathrm{GHz} \\
\text { mm-wave frequency } \\
\text { and RF amplifier }\end{array}$ \\
\hline$[14]$ & $\begin{array}{l}\text { SFDR amplification } \\
\text { strategy based on } \\
\text { single side band (SSB) } \\
\text { phase modulation }\end{array}$ & $\begin{array}{l}\text { Simple structure to } \\
\text { compensate } \\
\text { dispersion and } \\
\text { nonlinearity of } \\
\text { modulator }\end{array}$ & $\begin{array}{c}\text { Use erbium doped } \\
\text { fiber amplifier and } \\
\text { the system is not } \\
\text { converged OFDM } \\
\text { mm-wave }\end{array}$ \\
\hline
\end{tabular}


Table 1. Cont.

\begin{tabular}{|c|c|c|c|}
\hline Literature Review & $\begin{array}{l}\text { Approach/Methods } \\
\text { Discussed }\end{array}$ & Pros & Cons \\
\hline$[16,19]$ & $\begin{array}{c}\text { Use cascade least } \\
\text { mean square (LMS) } \\
\text { equalizer and } \\
\text { variable step } \\
\text { size equalizer }\end{array}$ & $\begin{array}{l}\text { Use electronic disper- } \\
\text { sion compensation }\end{array}$ & $\begin{array}{l}\text { BPSK is used and less } \\
\text { transmission distance }\end{array}$ \\
\hline [22] & $\begin{array}{l}\text { Modified CMA } \\
\text { is used }\end{array}$ & Simple algorithm & $\begin{array}{c}\text { Considered multi } \\
\text { path channel instead } \\
\text { of SMF }\end{array}$ \\
\hline [23] & $\begin{array}{l}\text { Joint equalization by } \\
\text { DD-LMS and } \\
\text { MCMA algorithm }\end{array}$ & Better equalization & $\begin{array}{l}\text { Complex algorithm } \\
\text { and considered multi } \\
\text { path channel instead } \\
\text { of SMF }\end{array}$ \\
\hline [24] & $\begin{array}{l}\text { Used blind nonlin- } \\
\text { ear compensator }\end{array}$ & $\begin{array}{l}\text { Compensates fiber } \\
\text { nonlinearity and long } \\
\text { reach system }\end{array}$ & $\begin{array}{l}\text { Use EDFA's for long } \\
\text { reach, expensive }\end{array}$ \\
\hline [This Work] & $\begin{array}{c}\text { Converged } \\
\text { OFDM-based } \\
\text { mm-wave A-RoF } \\
\text { system at } 60 \mathrm{GHz} \\
\text { with offline } \\
\text { signal processing }\end{array}$ & $\begin{array}{l}\text { Electronic dispersion } \\
\text { compensation in } \\
\text { Matlab, no amplifiers } \\
\text { used, cost } \\
\text { effective system }\end{array}$ & $\begin{array}{l}\text { Difficult to use higher } \\
\text { order modulation } \\
\text { formats in } \\
\text { such system }\end{array}$ \\
\hline
\end{tabular}

The paper is organized as follows. In Section 2, a complete converged 5G mm-wave A-RoF multicarrier OFDM digital communication system is explained. Section 3 provides the details of the different equalization algorithms used. Subsequently, the simulated setup and the error vector magnitude calculation are described in Sections 4 and 5, respectively; finally, Sections 6 and 7 present the results and conclusions.

\section{Converged 5G mm-wave A-RoF OFDM Digital Communication System}

OFDM, a multicarrier modulation approach, is broadly used in wireless and optical communication systems due to its high bandwidth capability and its ability to counter both inter-carrier interference (ICI) and inter-symbol interference (ISI) using a cyclic prefix (CP) [5]. OFDM, when utilized with high-order QAM, enhances the system's efficiency, permitting a high throughput with low errors. Figure 1 shows a very basic block diagram for an OFDM transceiver with a converged 5G mmWave A-RoF system.

A Pseudo-Random Binary Sequence (PRBS) is used to produce the bit rate, according to the modulation type and the used bitrate. The digital bits are divided into data flows, and each serial flow of input data is then converted to ' $n$ ' parallel bit flows of lower bitrates. In this way, symbol mapping is applied. Subsequently, the signal is modulated on to orthogonal subcarriers in the digital domain by applying the inverse fast Fourier transform (IFFT). Thus, a complex frequency domain signal is represented as a time domain signal. $\mathrm{A} C \mathrm{CP}$ is added after the IFFT to mitigate the inter-channel interference. The $\mathrm{CP}$ is a guard time interval placed at the start or at the end of each OFDM symbol after the IFFT. After adding the cyclic prefix, the parallel sub-channels are converted to serial sub-channels, and the resulting signal is fed into a DAC transforming the digital signal into the analog domain before transmitting the signal to a channel. Subsequently, a mm-wave signal at $60 \mathrm{GHz}$ is generated, and the converged mm-wave and A-RoF signals are sent to a SSMF with a dispersion $17 \mathrm{ps} / \mathrm{nm} / \mathrm{km}$. The signal is then sent to a photodetector to convert it to an electrical signal. 


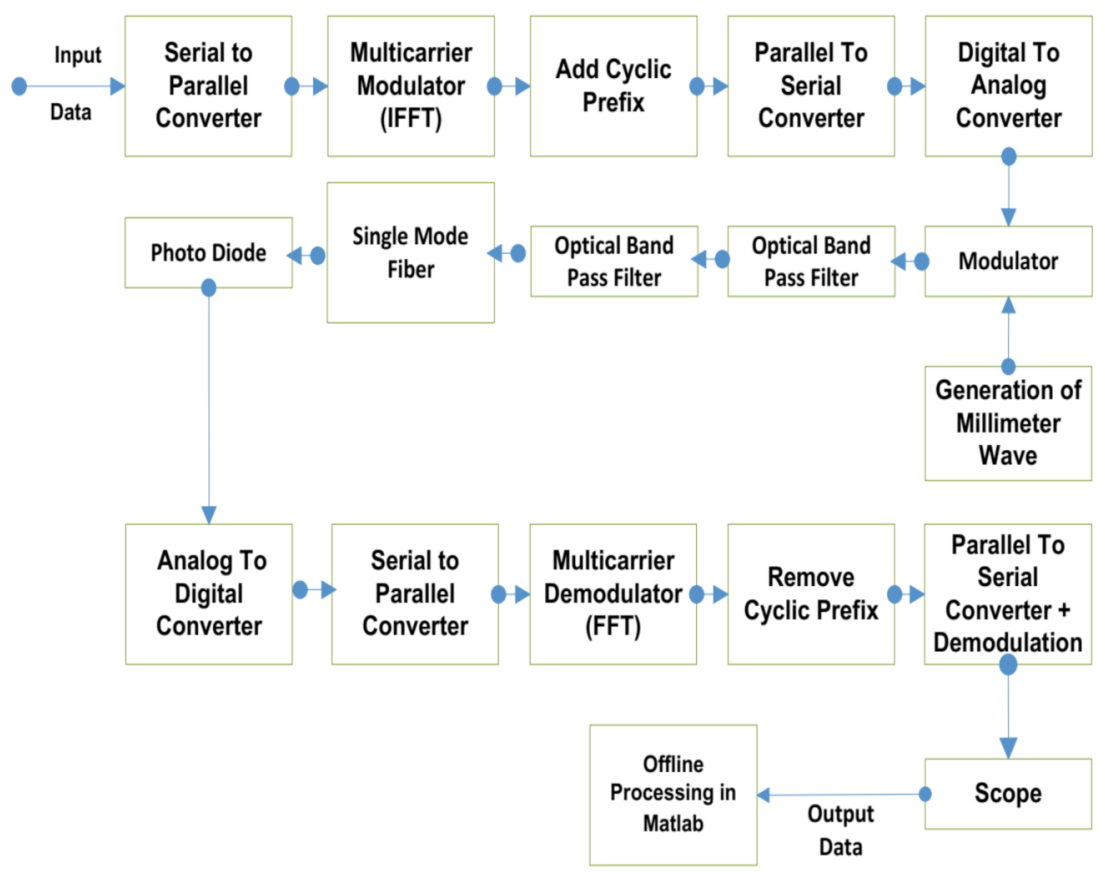

Figure 1. Block diagram of a converged $5 \mathrm{G}$ mm-wave A-RoF multicarrier OFDM digital communication system consisting of an OFDM transmission chain, mm-wave generation and an OFDM reception chain.

The bottom part of Figure 1 shows the structure of an OFDM decoder. The ADC is required to convert the continuous received signal into discrete samples. Serial to parallel conversion is performed, and the cyclic prefix is removed. After removing the cyclic prefix, the FFT procedure includes the subcarrier transformation in the digital domain [30], and the signal is then changed back to the frequency domain. The parallel bit streams are then fed into a parallel-to-serial converter, and the QAM demodulator converts the received symbols into bits.

\section{Different Equalization Algorithms}

In this section, the three equalization algorithms employed in our proposed converged OFDM-based 5G mm-wave A-RoF system at $60 \mathrm{GHz}$ are presented.

\subsection{Least Mean Square Algorithm}

The LMS is a very simple and robust algorithm that is broadly used in applications of digital filtering $[29,30]$ and signal processing. The simplicity of the algorithm is that the only value to be corrected is the step size ' $\mu$. The filter tap weights are adjusted during a reiterative process, and ultimately the filter minimizes the error signal between the equalizer output and the stored ideal signal [31]. An LMS algorithm can be realized as indicated in Figure 2 [32]. The required signal $\mathrm{j}(\mathrm{k})$ is trailed by modifying the filter coefficients $\mathrm{c}(\mathrm{k})$. The known ideal signal $\mathrm{g}(\mathrm{k})$ is then supplied to the finite impulse response filter (FIR). The difference between the desired signal and $y(k)-w h i c h$ is the exit of the filter-is the error signal e(k). The erroneous signal $\mathrm{e}(\mathrm{k})$ is then inserted into the LMS equalizer to calculate the filter coefficients $c(k+1)$ in order to reiteratively reduce the mean square error J.

$$
\mathrm{J}=\mathrm{E}\left\{\mathrm{e}^{2}(\mathrm{k})\right\}
$$

and the error signal is given by

$$
\begin{gathered}
j(k)-c^{T}(k) g(k) \\
c(k)=\left[c 1(k), c 2(k-1) \ldots, c L(c-L+1)^{T}\right.
\end{gathered}
$$


$\mathrm{w}(\mathrm{k})$ is the coefficient vector of filter length $\mathrm{L}$ or the number of taps, and

$$
\mathrm{g}(\mathrm{k})=\left[\mathrm{g}(\mathrm{k}), \mathrm{g}(\mathrm{k}-1) \ldots, \mathrm{g}(\mathrm{c}-\mathrm{L}+1)^{\mathrm{T}}\right.
$$

is the adaptive filter data vector. The update equation for the LMS equalizer is given by

$$
\mathrm{c}(\mathrm{k}+1)=\mathrm{c}(\mathrm{k})+2 \mu \mathrm{g}(\mathrm{k}) \mathrm{e}(\mathrm{k})
$$

where $\mathrm{g}(\mathrm{k}) \mathrm{e}(\mathrm{k})$ is the negative gradient, and $\mu$ is the step size [32,33]. The step size $\mu$ is a very important variable, and it should be selected to lie in the following range:

$$
0<\mu>\frac{1}{\mathrm{LP}_{\mathrm{x}}}
$$

where, $\mathrm{P}_{\mathrm{x}}$ is the input signal power. The convergence time of the LMS filter is the time that the filter converges; it is based on step size $\mu$. If $\mu$ is small, the filter converges very slowly; if $\mu$ is very large, the algorithm would not converge.

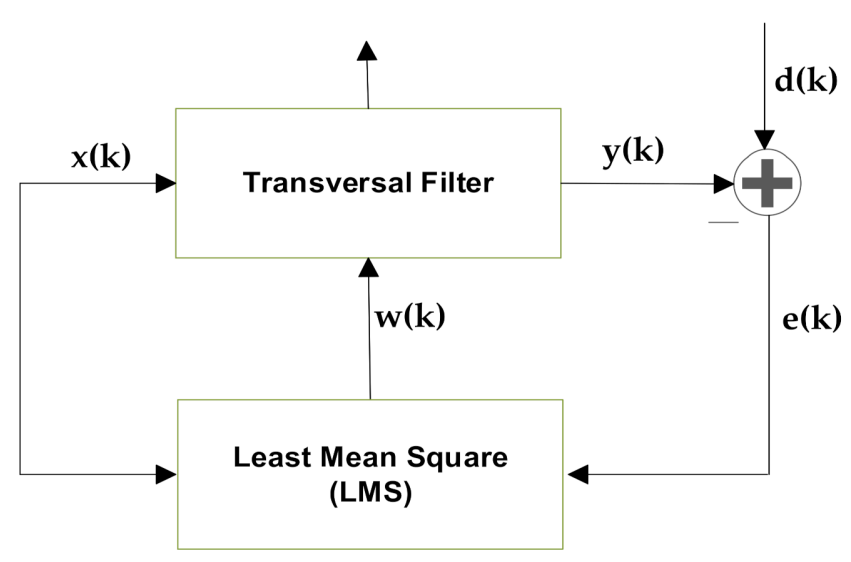

Figure 2. Block diagram and mathematical explanation of the implementation of the Least Mean Square (LMS) algorithm using a Finite Impulse Response (FIR) filter.

\subsection{Constant Modulus Algorithm}

The CMA $[34,35]$ is one of the most frequently employed blind equalization algorithm, as it works very satisfactorily for modulation formats in signal constellations with constant radii, like the Phase Shift Keying (PSK) modulation format. If multiple radii exist in constellation points, as in the case of 16QAM, the estimated error attained with the algorithm found on the constant modulus (CM) measure does not minimize after equalization. This is the reason for the undesirable performance of traditional $\mathrm{CM}$ algorithms with higher-order QAM signals [36].

The mathematical equation of CMA is given by

$$
\mathrm{J}(\mathrm{k})=\mathrm{E}\left[\left(\mathrm{y}(\mathrm{k})^{2}-\mathrm{R}_{2}\right)\right]^{2}
$$

where $y(k)$ is the equalizer output and $R_{2}$ is a constant which depends only on the input data symbols.

The output of the equalizer $\mathrm{y}(\mathrm{k})$ is given by

$$
\mathrm{y}(\mathrm{k})=\sum_{\mathrm{K}=0}^{\mathrm{L}-1} \mathrm{z}_{\mathrm{n}}(\mathrm{k}) \mathrm{d}(\mathrm{n}-\mathrm{k})
$$

Here, $\mathrm{d}(\mathrm{n})$ is the signal to be equalized, and $\mathrm{zn}(\mathrm{k})$ are the filter taps. where the equalizer tap weights vector is

$$
\mathrm{z}_{\mathrm{n}}=\left[\mathrm{z}_{\mathrm{o}}(\mathrm{k}), \mathrm{z}_{1}(\mathrm{k}), \ldots \ldots \mathrm{z}_{\mathrm{N}-1}(\mathrm{k})\right]^{\mathrm{T}}
$$


and

$$
\mathrm{d}(\mathrm{k})=[\mathrm{d}(\mathrm{k}), \mathrm{d}(\mathrm{k}-1), \ldots \ldots \mathrm{d}(\mathrm{k}-\mathrm{N}+1)]^{\mathrm{T}}
$$

where $\mathrm{d}(\mathrm{k})$ is the input data vector. ' $\mathrm{N}$ ' is the length of the tap weights of the equalizer; the superscript ' $T$ ' is the transpose of a vector. The tap weights vector is given by [37]

$$
\mathrm{z}(\mathrm{k}+1)=\mathrm{z}(\mathrm{k})+\mu \cdot \Delta \mathrm{J}(\mathrm{k})=\mathrm{z}(\mathrm{k})+\mu \cdot \mathrm{d}(\mathrm{k}) \mathrm{e}^{*}(\mathrm{k})
$$

where $\mu$ is the step size parameter, and the error signal is given [38] by

$$
e(k)=y(k)\left(R_{2}-|y(k)|^{2}\right)
$$

\subsection{Adaptive Median Filtering Algorithm}

The adaptive median filter (AMF) algorithm was proposed by Tukey [39] as an effective approach for the smoothing of signals. The median filter [40] is a basic rank selection filter. The principle of the median filter is to replace the occurrence of each pixel or constellation data point of the filtering window with the median of the occurrence of a neighborhood of all of the constellation data points within the window, instead of using the average operation.

Where $y(k)$ represents the input constellation value of the distorted constellation at position $\mathrm{k}$. At each position $\mathrm{k}$, the filter window $\mathrm{c}\{\mathrm{k}\}$ of size $\mathrm{N}=2 \mathrm{~m}+1$ ( $\mathrm{m}$ is a positive integer); it is described as

$$
\mathrm{c}\{\mathrm{k}\}=\{\mathrm{y}(\mathrm{k}): \mathrm{s}=1, \ldots, \mathrm{m}, \mathrm{m}+1, \ldots, \mathrm{N}\}
$$

The median filter $\mathrm{u}(\mathrm{k})$ is the resultant value at position $\mathrm{k}$ in a filter window which is given by [41]

$$
\mathrm{u}(\mathrm{k})=\operatorname{med}\{\mathrm{x} 1(\mathrm{k}), \ldots \mathrm{xN}(\mathrm{k})\}
$$

where med is the median operator.

\section{Simulation Setup}

The simulation setup is the illustration of the converged mm-wave $60 \mathrm{GHz}$ A-RoF system with offline signal processing in Matlab. The setup used is shown in Figure 1, while detailed figures of the different components are shown in Figures 3-5.

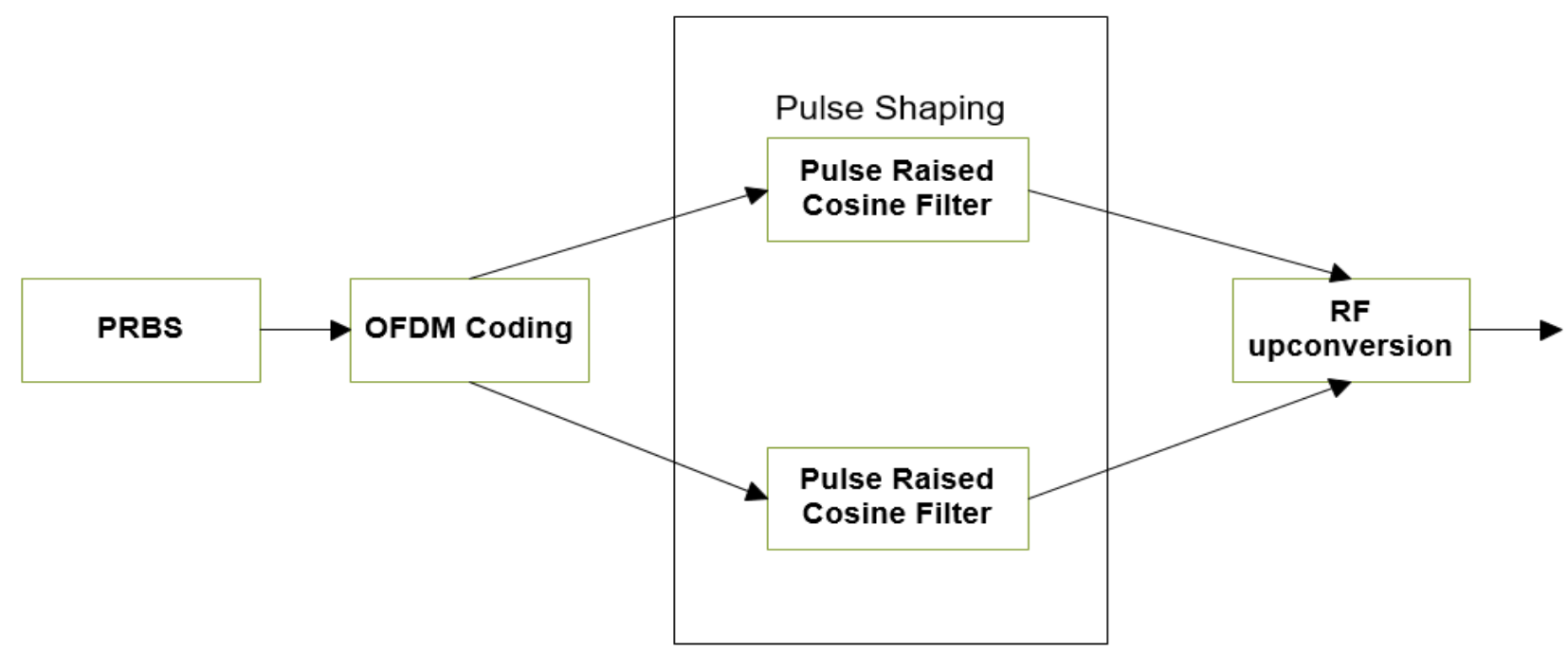

Figure 3. Block diagram of the implementation of the Orthogonal Frequency Division Multiplexing (OFDM) transmitter. PRBS: Pseudorandom Binary Sequence; RF: Radio Frequency. 


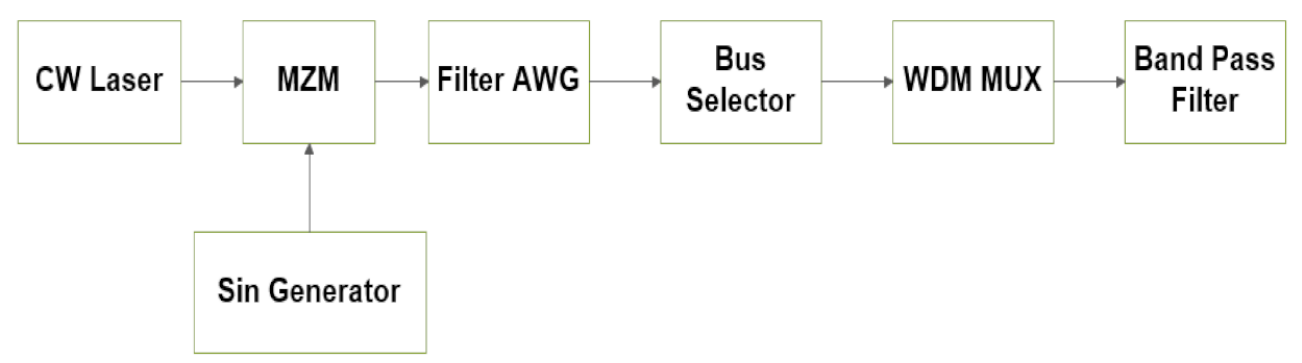

Figure 4. Block diagram of the generation of millimeter waves. CW: Constant Wave; MZM: MachZehnder Modulator; AWG: Arrayed Wavelength Grating; WDM: Wavelength Division Multiplexing; MUX: Multiplexer.

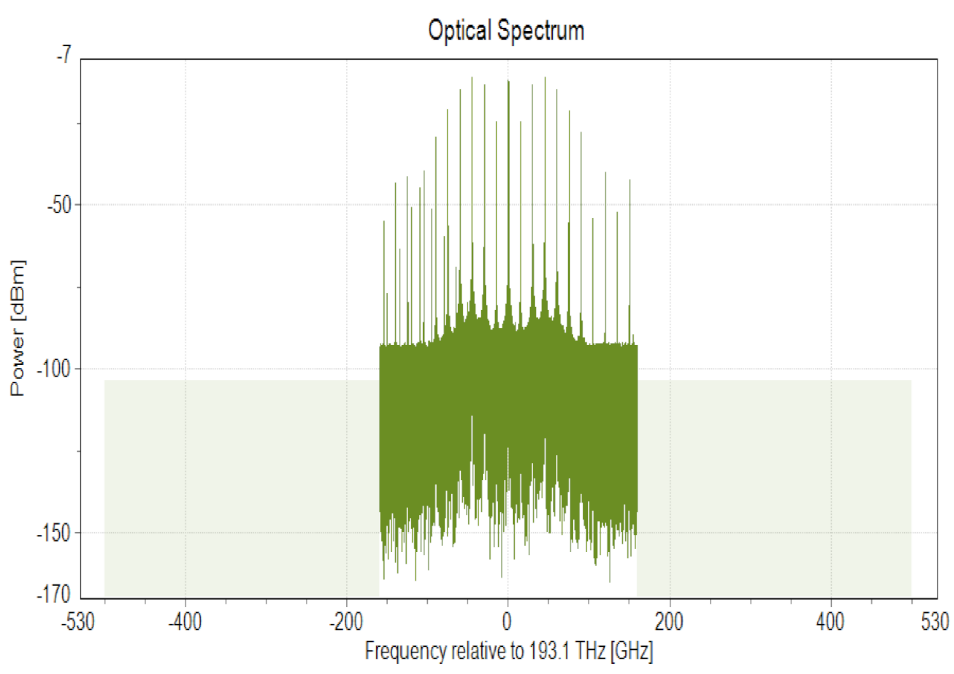

Figure 5. Optical Spectrum obtained after the Mach-Zehnder modulator (MZM). The spectrum consists of sidebands with frequency spacing equal to $15 \mathrm{GHz}$.

The transmitter in the OFDM module (detailed in Figure 3) consists of a PRBS module for the generation of the bit rate. The digital binary bits are encoded in the coder block. After the coding stage, pulse-shaping is performed by a raised cosine filter. By filtering the transmitted pulses, the ISI caused by the channel can be regulated. Next, an OFDM signal is up-converted to an RF carrier frequency of $7.5 \mathrm{GHz}$, with multilevel QPSK and 16 QAM coded symbols.

After up-conversion, the signal goes to MZM. The signal after the MZM is comprised of many sub-bands, as indicated in Figure 5, with the frequency division between two subsequent bands being equal to $15 \mathrm{GHz}$. The modulated signal is then transmitted over an arrayed waveguide grating (AWG) block, and among successive channels the frequency separation is modified. Finally, a 'Bus Selector' block is employed to choose the correct bands separated by $60 \mathrm{GHz}$, as shown in Figure 6. 


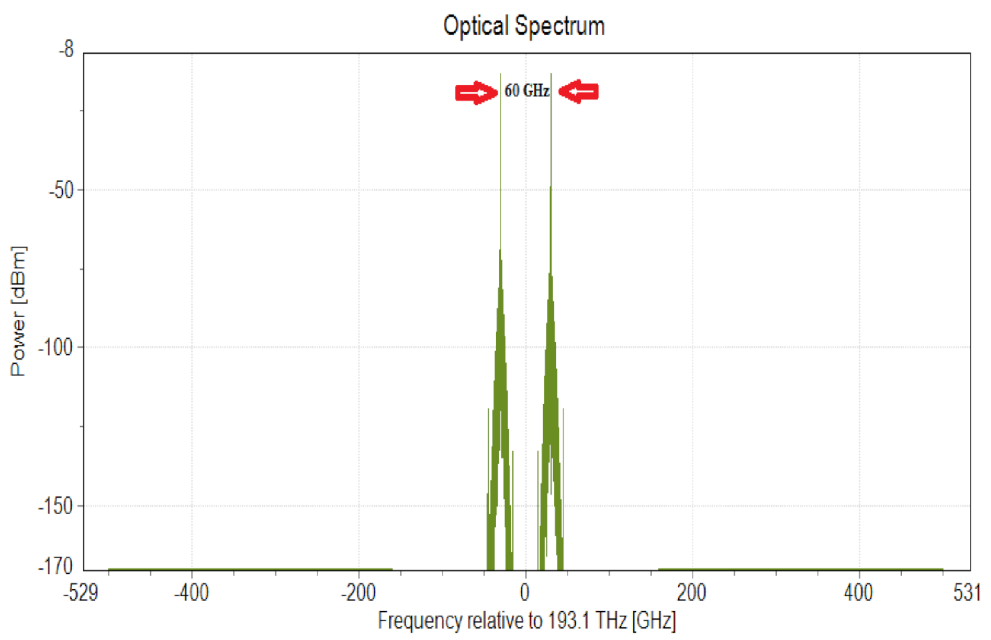

Figure 6. Spectrum obtained after the selection of mm-wave frequency $(60 \mathrm{GHz})$ sidebands by a bus selector module from different sidebands.

The two sidebands are then merged into a single sideband by a 'WDM_MUX' module. Subsequently, OFDM signals and the generated $\mathrm{mm}$-wave $60 \mathrm{GHz}$ are sent through an SSMF with a dispersion value of $17 \mathrm{ps} / \mathrm{nm} / \mathrm{km}$. A single photodiode is used to catch the optical signal, and then the electrical signal is sent to an OFDM receiver-as shown in Figure 7-to recover the subcarriers.

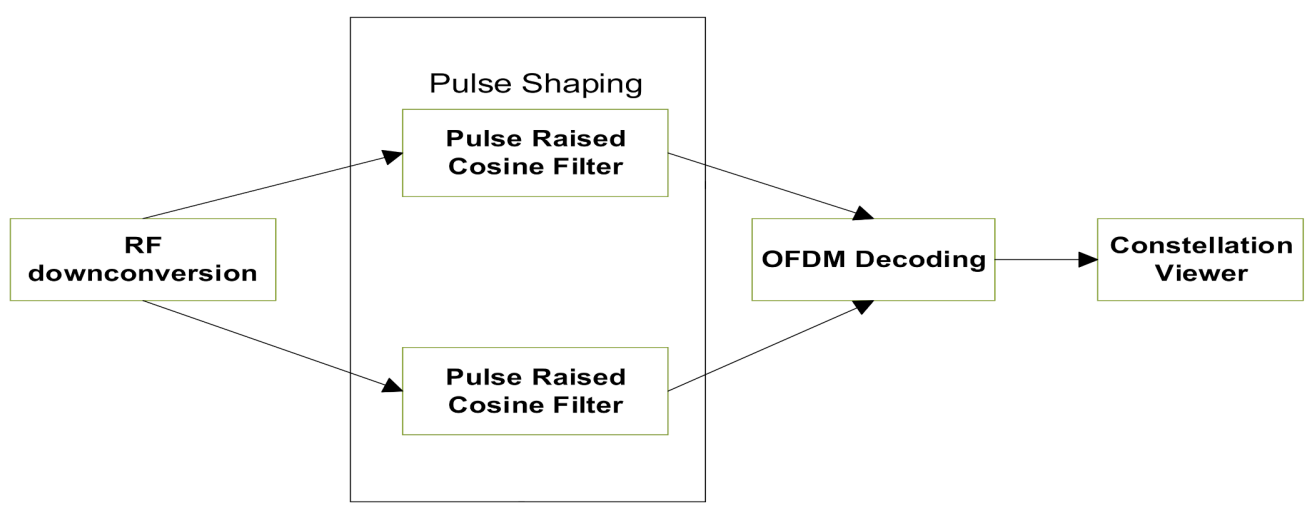

Figure 7. Block representation of the implementation of the OFDM receiver consisting of pulse raised cosine filters, an OFDM decoder and a constellation viewer. RF: Radio Frequency.

The electrical signal is down-converted to a baseband signal, and pulse shaping is performed in the next stage. After pulse shapingthe signal is then sent to an OFDM decoder. After the completion of the decoding process, the distorted symbols from the OFDM constellation analyzer are captured and then equalized in Matlab by the LMS, CMA and AMF algorithms. Table 2 summarizes the simulation parameters used in this work. 
Table 2. Simulation parameters.

\begin{tabular}{cc}
\hline Link Design Components & Values \\
\hline Carrier Frequency & $7.5 \mathrm{GHz}$ \\
\hline Laser CW & $10 \mathrm{dBm}$ \\
\hline Wavelength & $1553 \mathrm{~nm}$ \\
\hline RIN & $-130 \mathrm{~dB} / \mathrm{Hz}$ \\
\hline SSMF Length & $0-100 \mathrm{~km}$ \\
\hline Dispersion & $17 \mathrm{ps} / \mathrm{nm} / \mathrm{km}$ \\
\hline Dispersion Slope & $0.08 \times 10^{3} \mathrm{~s} / \mathrm{m}^{3}$ \\
\hline Photo Diode Model & $\mathrm{PIN}$ \\
\hline Responsivity & $0.8 \mathrm{~A} / \mathrm{W}$ \\
\hline Thermal Noise & $10^{-12} \mathrm{~A} / \mathrm{Hz}^{1 / 2}$ \\
\hline Shot Noise & $\mathrm{ON}$ \\
\hline
\end{tabular}

\section{Error Vector Magnitude Calculation}

After the equalization of the distorted constellation in Matlab, the EVM of the equalized constellation diagram is computed. Figure 8 depicts the computation of the EVM; the equation used to compute the EVM is given by $[42,43]$.

$$
\mathrm{EVM}=1 / \mathrm{N}\left[\frac{\sum_{\mathrm{n}=1}^{\mathrm{N}}\left(\left|\mathrm{S}_{\text {reference, } \mathrm{n}}-\mathrm{S}_{\text {measured }, \mathrm{n}}\right|\right)^{2}}{\sum_{\mathrm{n}=1}^{\mathrm{N}}\left(\left|\mathrm{S}_{\text {reference, } \mathrm{n}}\right|\right)^{2}}\right]^{1 / 2}
$$

where Sreference, $\mathrm{n}$ is the ideal $\mathrm{nth}$ symbol, and Smeasured, $\mathrm{n}$ is the $\mathrm{n}$ th measured symbol.

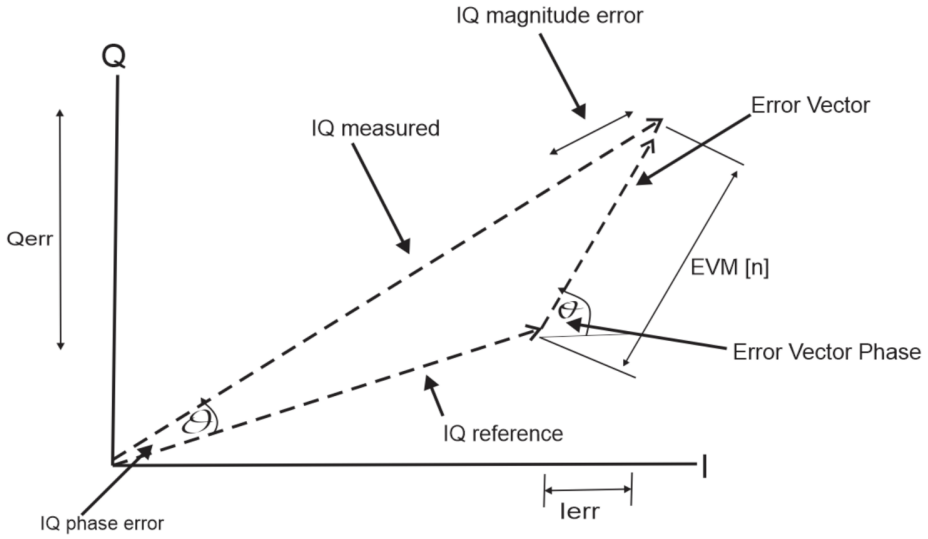

Figure 8. Mathematical explanation of the different vectors required for the calculation of the Error Vector Magnitude (EVM).

\section{Results}

The output signal of the given setup shown in Figure 1 suffers from chromatic dispersion in an SSMF, degrading the resulting signal. The method used in this work for the compensation of the distortion, as discussed in Section 3, consists of the processing of the signal offline using different equalization algorithms, such as the least mean square, constant modulus, and median filtering. We applied the QPSK modulation technique in the OFDM subcarriers in all three of the above-mentioned algorithms, while for 16QAM we applied the LMS and AMF algorithms for equalization. We didn't use the CMA algorithm because the constellation points were characterized by multiple radii, such that this algorithm would not work in this case. 


\subsection{Equalization by the Least Mean Square Algorithm}

The LMS equalization was performed on the distorted data obtained from the OFDM receiver. Figures 9 and 10 show the constellation diagrams of QPSK and 16QAM obtained before and after the equalization. After equalization, the EVM of the equalized constellations was computed using Equation (15).

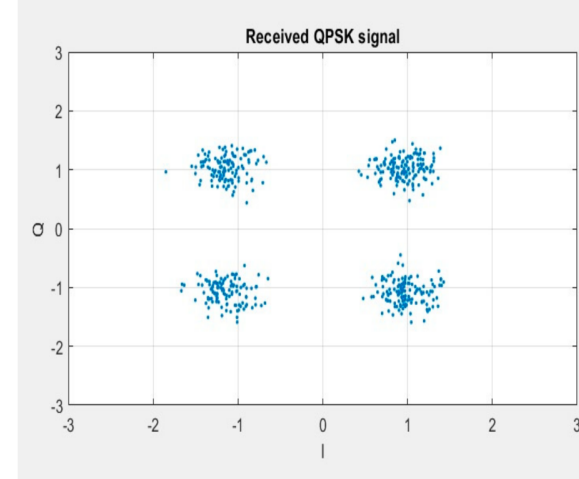

(a)

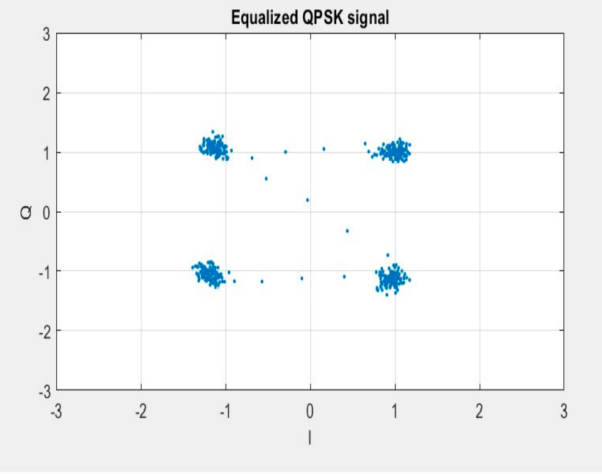

(b)

Figure 9. EVM measurements for the QPSK modulation using LMS equalization (100 km SMF link). (a) Constellation diagram for QPSK before equalization with EVM 18.7\%. (b) Constellation diagram for QPSK after LMS equalization with EVM 17\%.

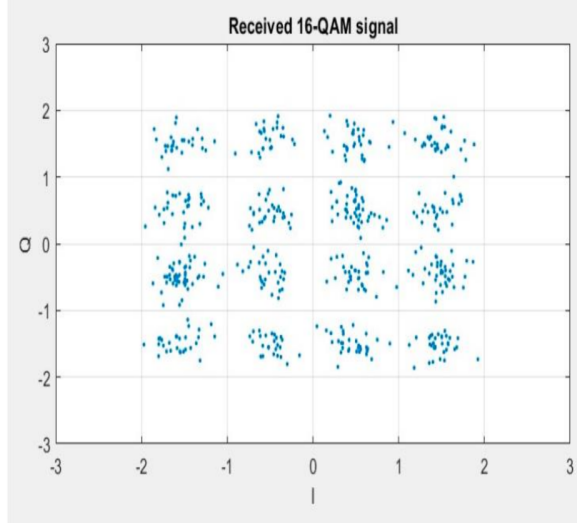

(a)

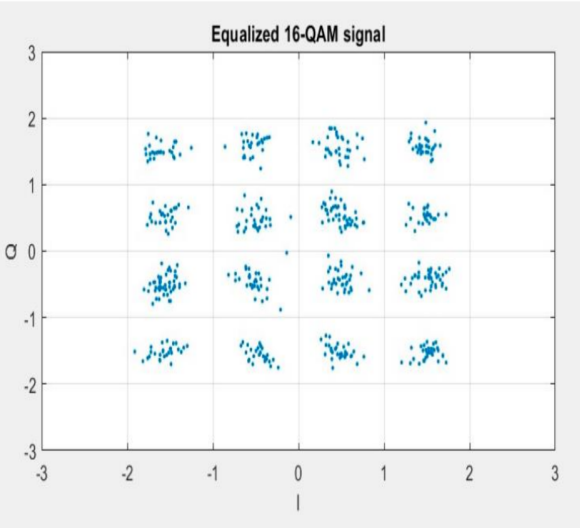

(b)

Figure 10. EVM measurements for 16QAM modulation using LMS equalization (50 km SMF link). (a) Constellation diagram for 16QAM before equalization with EVM 15.1\%. (b) Constellation diagram for 16QAM after LMS equalization with EVM 12\%.

The implementation of the proposed LMS algorithm is examined with different fiber lengths in the presence of dispersion. It was observed that for QPSK modulation in OFDM subcarriers and a maximum fiber length of $100 \mathrm{~km}$, we obtained an EVM of $17 \%$ after equalization, while for 16QAM modulation in OFDM subcarriers and a maximum fiber length of $50 \mathrm{~km}$ we obtained an EVM of $12 \%$ after equalization, both of which are below the 3GPP threshold. We obtained an EVM improvement of $1.7 \%$ for QPSK and 3.1\% for 16QAM after LMS equalization for the same fiber length.

Figures 11 and 12 present the EVM results versus the fiber length both for QPSK and 16QAM, revealing that an LMS equalizer can be applied effectively to provide dispersion in a converged mm-wave A-RoF system at $60 \mathrm{GHz}$. 


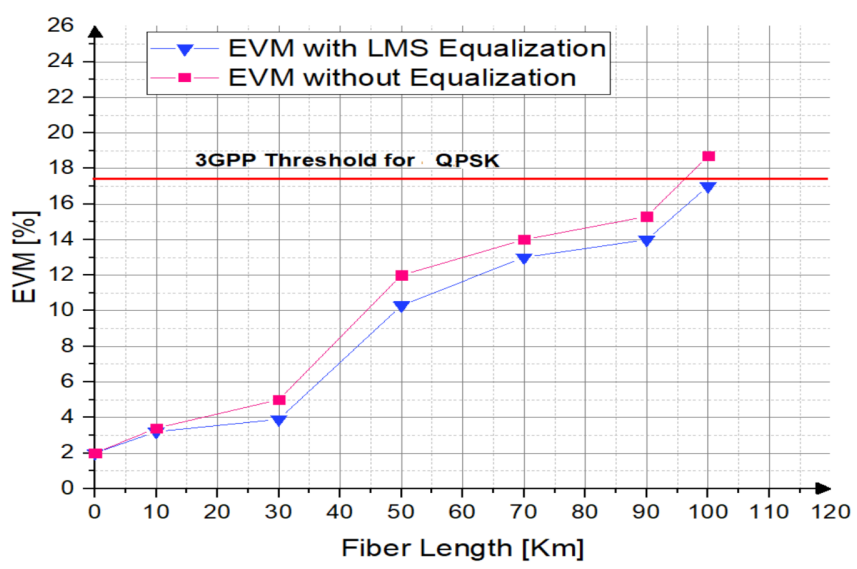

Figure 11. EVM results obtained before and after equalization vs. the fiber lengths for a QPSK constellation.

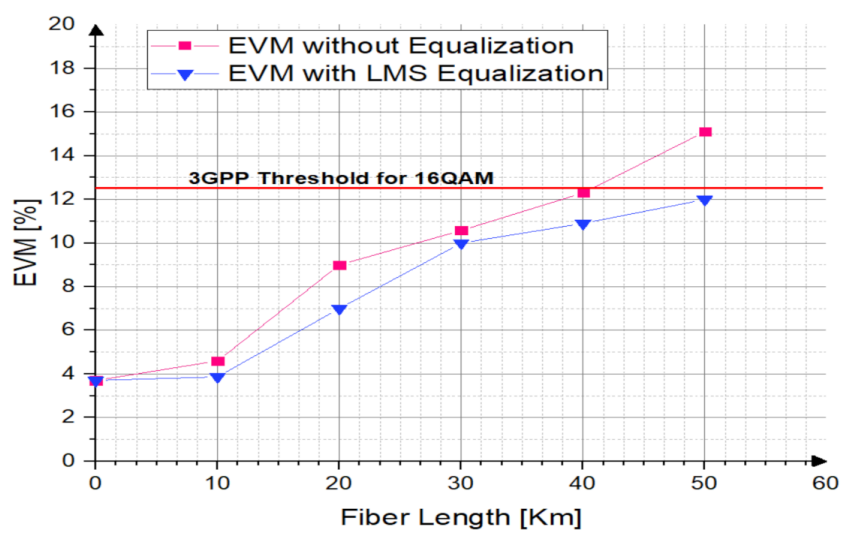

Figure 12. EVM results obtained before and after Least Mean Square (LMS) equalization vs. the fiber lengths for a 16QAM constellation.

\subsection{Equalization by the CMA Algorithm}

The blind channel equalization or constant modulus algorithm was applied to the received data, as described by Section 3.2. The distorted OFDM subcarrier signals with the QPSK modulation format resulting in the constellation diagram and EVM calculations are shown in Figures 13 and 14. The implementation of the proposed CMA algorithm is examined with different fiber lengths in the presence of dispersion.

It was observed that for QPSK modulation in OFDM subcarriers and a maximum fiber length of $100 \mathrm{~km}$, we obtained an EVM of $15 \%$ after equalization. We obtained an EVM improvement of $3.7 \%$ for QPSK after CMA equalization for the same fiber lengths. When we compared the CMA with the LMS algorithm in terms of EVM, in the case of CMA we obtained a $2 \%$ further improvement in EVM. 


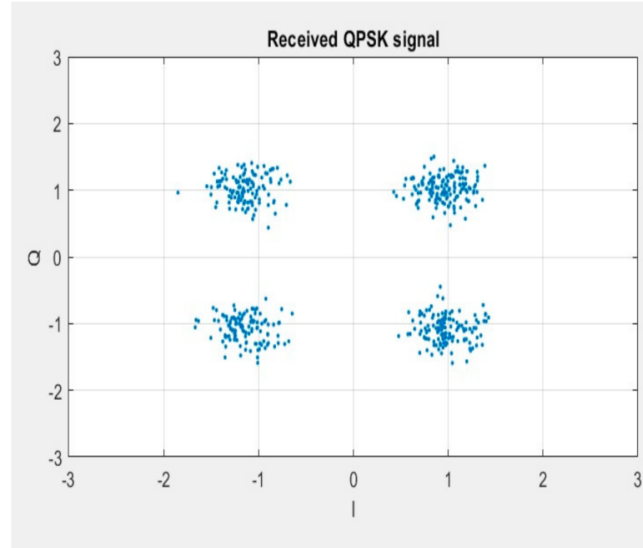

(a)

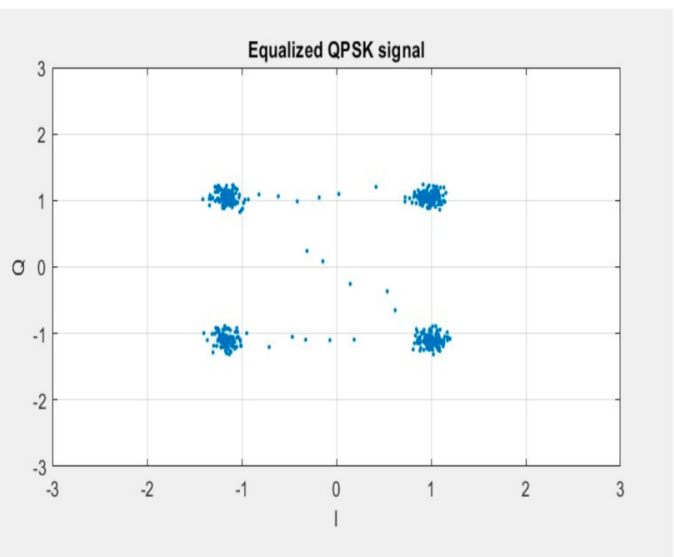

(b)

Figure 13. EVM measurements for QPSK modulation using CMA equalization (100 km SMF link). (a) Constellation diagram for QPSK before equalization with EVM 18.7\%. (b) Constellation diagram for QPSK after CMA equalization with EVM 15\%.

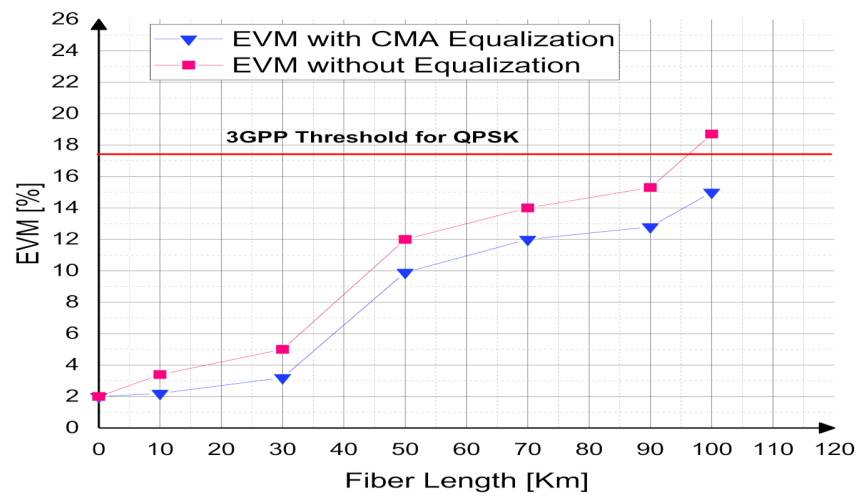

Figure 14. EVM results obtained before and after Constant Modulus Algorithm (CMA) equalization vs the fiber lengths for the QPSK constellation.

\subsection{Equalization by Median Filtering}

The third algorithm is adaptive median filtering (AMF), as described in Section 3.3. We also performed offline signal processing on the distorted data of the QPSK and 16QAM OFDM subcarriers, and the implementation of the proposed MF algorithm was examined with different fiber lengths in the presence of dispersion. It was observed that for QPSK modulation in OFDM subcarriers and a maximum fiber length of $100 \mathrm{~km}$, we obtained an EVM of $16.4 \%$ after equalization, while for 16QAM modulation in OFDM subcarriers and a maximum fiber length of $50 \mathrm{~km}$ we obtained an EVM of $12.2 \%$ after equalization, both of which were below the 3GPP [44] threshold limit. We obtained an EVM improvement of $2.3 \%$ for QPSK and 2.9\% for 16QAM after MF equalization for the same fiber length.

The constellation diagrams obtained after MF equalization are shown by Figures 15 and 16, for the QPSK and 16QAM modulation scheme applied in each OFDM subcarrier, respectively.

Figures 17 and 18 present the different EVM results tested with different fiber lengths both for QPSK and 16QAM, revealing that the proposed method of MF equalization technique can be applied effectively in order to eliminate dispersion in a converged $\mathrm{mm}$ wave A-RoF system at $60 \mathrm{GHz}$.

Figures 19 and 20 present the different EVM results for varying input powers with a fixed fiber length both for QPSK and 16QAM, along with the 3GPP threshold for the two cases. Figure 19 shows that for the fixed fiber length of $70 \mathrm{~km}$ and QPSK modulation, when the power is very low the EVM values are high; however, as the power increases 
from $3 \mathrm{dBm}$ to $13 \mathrm{dBm}$ the EVM values decrease, and after $7 \mathrm{dBm}$ of power the values are below the 3GPP threshold limit. Thus, in the cases where the power is below $7 \mathrm{dBm}$ or the length of the fiber is increased, there is also in this modulation format a need for equalization in the proposed setup.

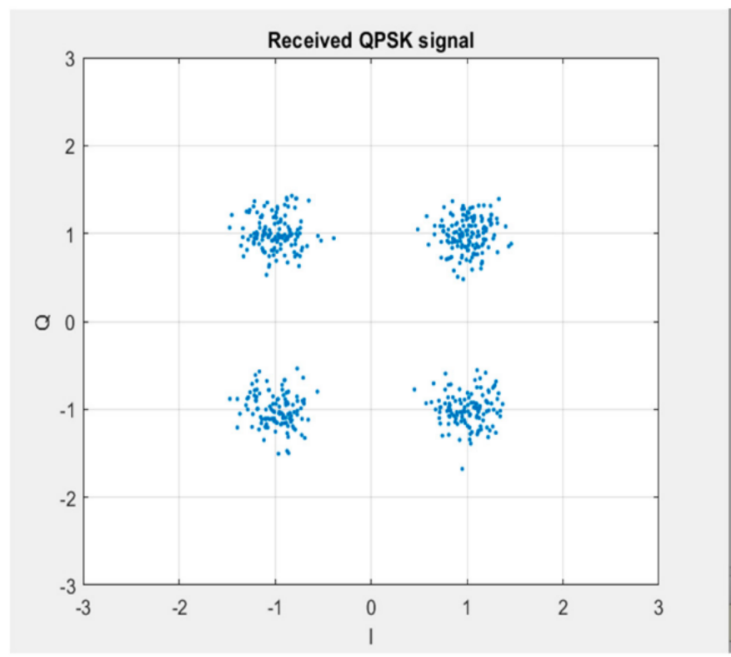

(a)

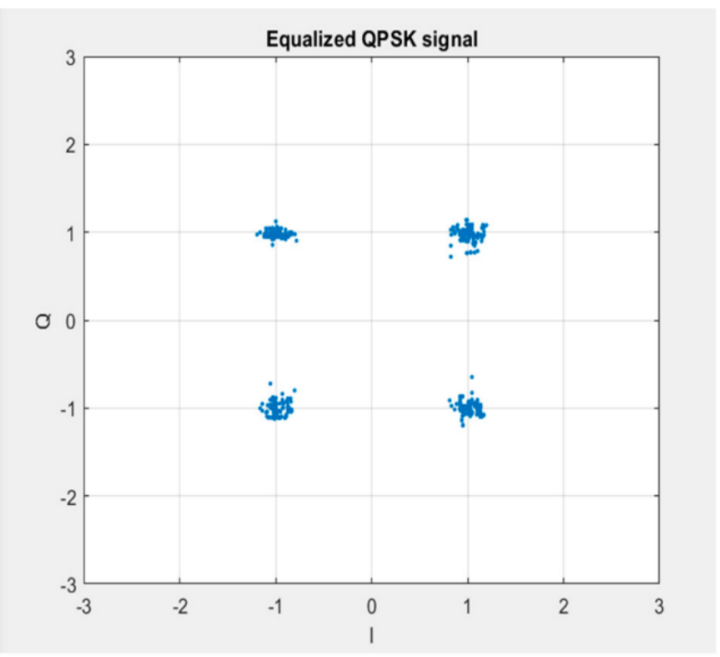

(b)

Figure 15. EVM measurements for QPSK modulation using MF equalization (100 km SMF link). (a) Constellation diagram for QPSK before equalization with EVM 18.7\%. (b) Constellation diagram for QPSK after MF equalization with EVM 16.4\%.

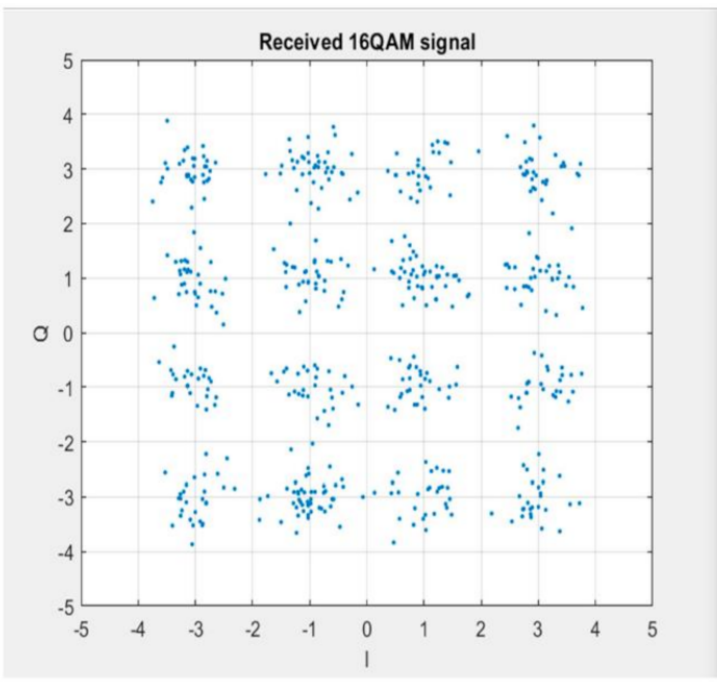

(a)

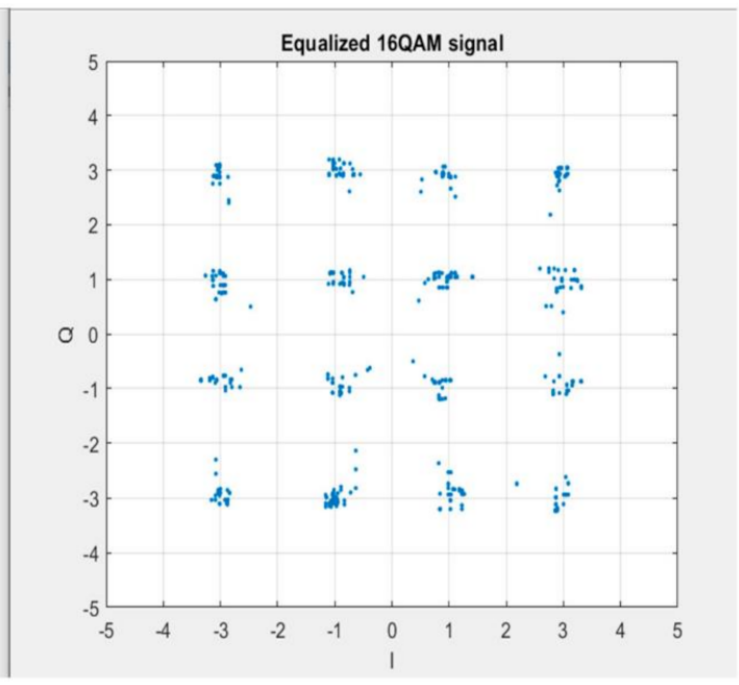

(b)

Figure 16. EVM measurements for 16QAM modulation using MF equalization (50 km SMF link). (a) Constellation diagram for 16QAM before equalization with EVM 15.1\%. (b) Constellation diagram for 16QAM after LMS equalization with EVM 12.2\%. 


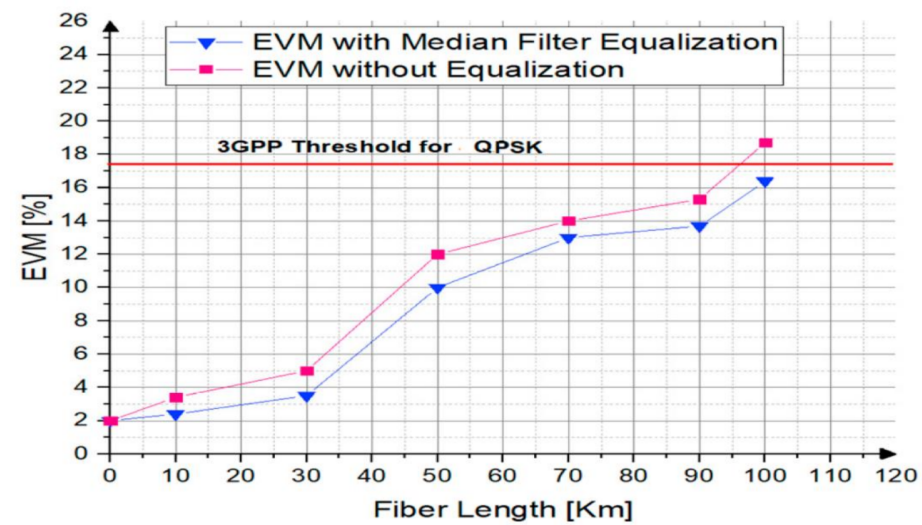

Figure 17. EVM results obtained before and after median filter equalization vs. the fiber lengths for the QPSK constellation.

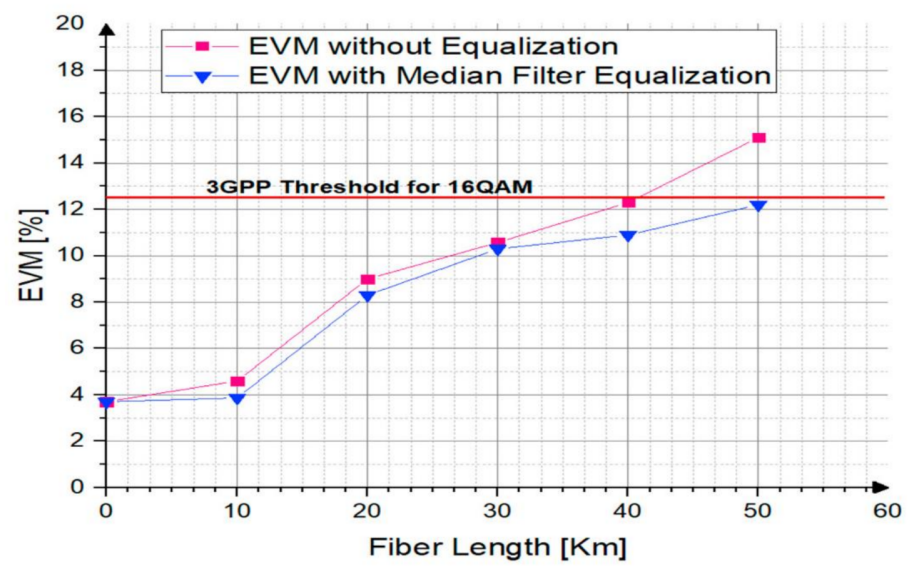

Figure 18. EVM results obtained before and after median filter equalization vs. the fiber lengths for the 16QAM Constellation.

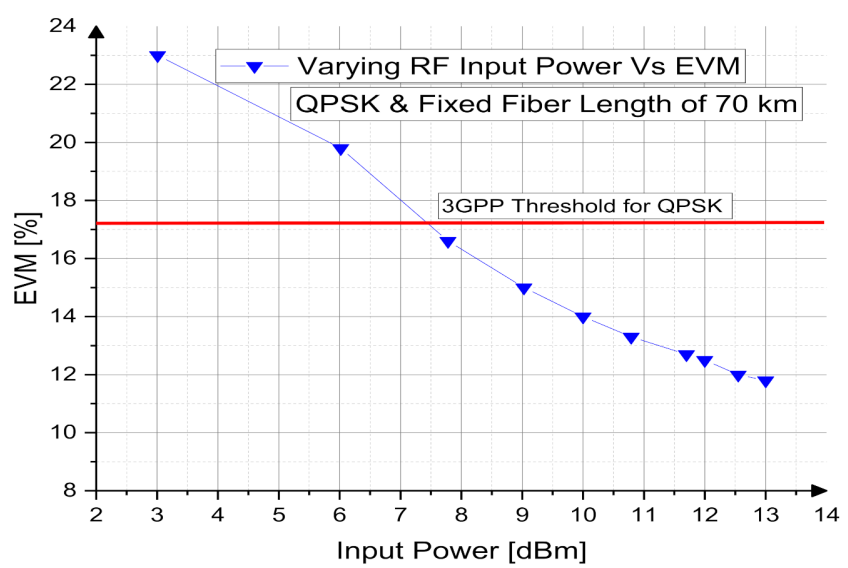

Figure 19. EVM results obtained for varying RF input power levels for a fixed fiber length of $70 \mathrm{~km}$ using QPSK as a modulation format. 


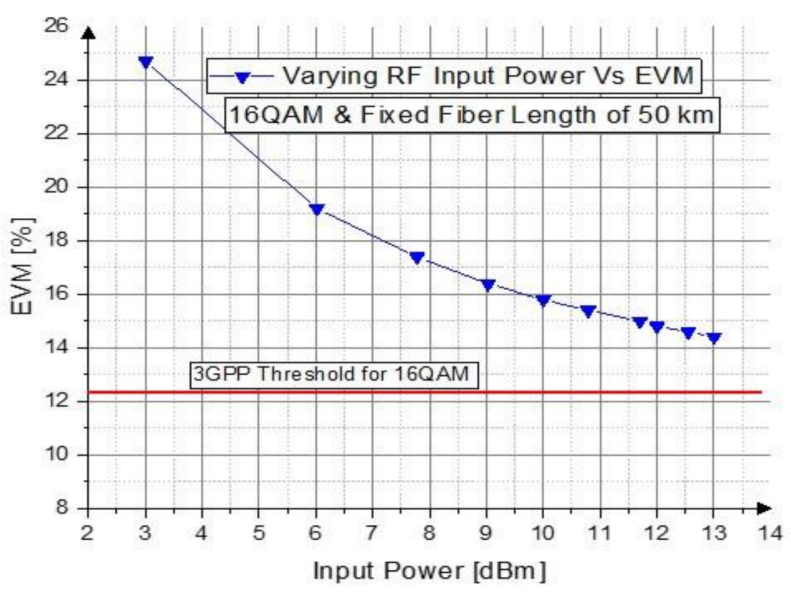

Figure 20. EVM results obtained for varying RF input power levels for a fixed fiber length of $50 \mathrm{~km}$ using 16QAM as the modulation format.

Similarly, Figure 20 presents the EVM performance for the fixed fiber length of $50 \mathrm{~km}$, and for 16QAM. When the power is low the EVM values are high, and as soon as the power increases the EVM decreases. Thus, there is a need for equalization in order for the EVM values to be below the 3GPP threshold limit for 16QAM.

\section{Conclusions}

A converged 5G mm-wave A-RoF system at $60 \mathrm{GHz}$ was presented. DSP algorithms such as LMS, CMA and AMF were implemented in Matlab in order to eliminate the dispersion in an SSMF, which downgrades the system performance. In the case of QPSK, CMA performs better than the LMS and AMF algorithms, and also we obtained an EVM improvement of $3.7 \%$ after equalization. For 16QAM, the LMS algorithm performs better than the MF algorithm, and we obtained an EVM improvement of 3\% after equalization. However, in the case of complexity, the AMF algorithm is the least complex among the other two because it does not depend on the convergence coefficient ' $\mu$ '.

Author Contributions: Conceptualization, U.F. and A.M.; methodology, U.F.; software, U.F.; validation, U.F., A.M.; formal analysis, U.F.; investigation, U.F.; resources, A.M.; data curation, U.F.; writing—original draft preparation, U.F.; writing—review and editing, A.M.; visualization, U.F.; supervision, A.M.; project administration, A.M.; funding acquisition, A.M. All authors have read and agreed to the published version of the manuscript.

Funding: The work presented in this article was carried out within the 5G STEP FWD Innovative Training Network, which has received funding from the European Union's Horizon 2020 Research and Innovation Programme 2018-2021 under the Marie Skáodowska-Curie Action grant agreement No.722429.

Institutional Review Board Statement: Not applicable.

Informed Consent Statement: Not applicable.

Data Availability Statement: Not applicable.

Conflicts of Interest: The authors declare no conflict of interest.

\section{References}

1. G.989.1: 40-Gigabit-Capable Passive Optical Networks (NG-PON2): General Requirements. Available online: https://www.itu. int/rec/T-REC-G.989.1/e (accessed on 15 December 2021).

2. Nesset, D. NG-PON2 Technology and Standards. J. Lightwave Technol. 2015, 33, 1136-1143. [CrossRef]

3. Okumura, Y.; Terada, J. Optical Network Technologies and Architectures for Backhaul/Fronthaul of Future Radio Access Supporting Big Mobile Data. In Proceedings of the Optical Fiber Communication Conference, San Francisco, CA, USA, 9-13 March 2014. 
4. Ishimura, S.; Bekkali, A.; Tanaka, K.; Nishimura, K.; Suzuki, M. 1.032-Tb/s CPRI-Equivalent Rate IF-Over-Fiber Transmission Using a Parallel IM/PM Transmitter for High-Capacity Mobile Fronthaul Links. J. Lightwave Technol. 2018, 36, 1478-1484. [CrossRef]

5. Yu, H.; Doylend, J.; Lin, W.; Nguyen, K.; Liu, W.; Gold, D.; Dahal, A.; Jan, C.; Herrick, R.; Ghiurcan, G.A.; et al. 100Gbps CWDM4 Silicon Photonics Transmitter for 5G Applications. In Proceedings of the Optical Fiber Communication Conference, San Diego, CA, USA, 3-7 March 2019.

6. Lim, C.; Tian, Y.; Ranaweera, C.; Nirmalathas, T.; Wong, E.; Lee, K. Evolution of Radio-Over-Fiber Technology. J. Lightwave Technol. 2019, 37, 1647-1656. [CrossRef]

7. Dat, P.T.; Kanno, A.; Inagaki, K.; Kawanishi, T. High-Capacity Wireless Backhaul Network Using Seamless Convergence of Radio-over-Fiber and 90-GHz Millimeter-Wave. J. Lightwave Technol. 2014, 32, 3910-3923. [CrossRef]

8. Cui, Y.; Xu, K.; Dai, J.; Sun, X.; Dai, Y.; Ji, Y.; Lin, J. Overcoming Chromatic-Dispersion-Induced Power Fading in ROF Links Employing Parallel Modulators. IEEE Photonics Technol. Lett. 2012, 24, 1173-1175. [CrossRef]

9. Rzaiqui, H.; Poette, J.; Cabon, B.; Brendel, F.; Khayatzadeh, R. Optical Heterodyning for Reduction of Chromatic Dispersion Sensitivity in $60 \mathrm{Ghz}$ Mode-Locked Lasers Systems. IEEE J. Lightwave Technol. 2017, 29, 2059-2062. [CrossRef]

10. Salman, A.; Zafrullah, M. 40 Gb/S 4-QAM OFDM Radio over Fiber System at 60 Ghz Employing Coherent Detection. J. Mod. Opt. 2015, 62, 296-301. [CrossRef]

11. Li, X.; Xiao, X.; Xu, Y.; Wang, K.; Zhao, L.; Xiao, J.; Yu, J. Real-Time Demonstration of over 20Gbps V-and W-Band Wireless Transmission Capacity in One OFDM-Rof System. In Proceedings of the Optical Fiber Communication Conference, Los Angeles, CA, USA, 19-23 March 2017; pp. 1-3.

12. Ilgaz, M.A.; Batagelj, B. Application of an Opto-Electronic Oscillator In 5G Mobile and Wireless Networks with a Low Frequency Drift, a High Side-Modes-Suppression Ratio and without a Power Penalty Due to Chromatic Dispersion. In Proceedings of the 2018 European Conference on Networks and Communications (EuCNC), Valencia, Spain, 18-21 June 2018. [CrossRef]

13. James, J.; Shen, P.; Nkansah, A.; Liang, X.; Gomes, N.J. Nonlinearity and Noise Effects in Multi-Level Signal MillimeterWave Over Fiber Transmission Using Single and Dual Wavelength Modulation. IEEE Trans. Microw. Theory Tech. 2010, 58, 3189-3198. [CrossRef]

14. Chen, Z.; Yan, L.; Pan, W.; Luo, B.; Zou, X.; Guo, Y.; Jiang, H.; Zhou, T. SFDR Enhancement in Analog Photonic Links by Simultaneous Compensation for Dispersion and Nonlinearity. Opt. Express 2013, 21, 20999-21009. [CrossRef]

15. Zhang, X.; Zhu, R.; Shen, D.; Liu, T. Linearization Technologies for Broadband Radio-Over-Fiber Transmission Systems. Photonics 2014, 1, 455-472. [CrossRef]

16. Liu, S.; Shen, G.; Kou, Y.; Tian, H. Special Cascade LMS Equalization Scheme Suitable for 60-Ghz Rof Transmission System. Opt. Express 2016, 24, 10599-10610. [CrossRef] [PubMed]

17. Nanni, J.; Polleux, J.-L.; Algani, C.; Rusticelli, S.; Perini, F.; Tartarini, G. VCSEL-Based Radio-Over-G652 Fiber System for Short-/Medium-Range MFH Solutions. J. Lightwave Technol. 2018, 36, 4430-4437. [CrossRef]

18. Hadi, M.U.; Jung, H.; Ghaffar, S.; Traverso, P.A.; Tartarini, C. Optimized Digital Radio over Fiber System for Medium Range Communication. Opt. Commun. 2019, 443, 177-185. [CrossRef]

19. Liu, S.; Shen, G.; Tian, H. A 60-Ghz Rof System Employing Variable Step Size LMS Equalizer with Fast Convergence Speed. In Proceedings of the Optical Fiber Communication Conference, Anaheim, CA, USA, 20-22 March 2016.

20. Hadi, M.U.; Traverso, P.A.; Tartarini, G.; Venard, O.; Baudoin, G.; Polleux, J.-L. Digital Predistortion for Linearity Improvement of VCSEL-SSMF-Based Radio-Over-Fiber Links. IEEE Microw. Wirel. Compon. Lett. 2019, 29, 155-157. [CrossRef]

21. Hadi, M.U.; Awais, M.; Raza, M.; Khurshid, K.; Jung, H. Neural Network DPD for Aggrandizing SM-VCSEL-SSMF-Based Radio over Fiber Link Performance. Photonics 2021, 8, 19. [CrossRef]

22. Asharif, F.; Tamaki, S.; Alsharif, M.R.; Ryu, H.G. Performance Improvement of Constant Modulus Algorithm Blind Equalizer for 16 QAM Modulation. Int. J. Innov. Comput. Inf. Control. 2013, 7, 1377-1384.

23. Zhang, J.; Zeng, X. Blind Equalization Algorithm for 16-QAM Signals. In Proceedings of the 2018 8th International Conference on Manufacturing Science and Engineering (ICMSE 2018), Shenzhen, China, 30-31 March 2018. [CrossRef]

24. Zhou, J.; Zhang, Y. Blind Time Domain Nonlinear Compensator Embedded in The Constant Modulus Algorithm. Opt. Express 2019, 27, 22794-22807. [CrossRef]

25. VPIphotonics: Simulation Software and Design Services. Available online: https://www.vpiphotonics.com/ (accessed on 1 December 2021).

26. Parker, M. Digital Signal Processing 101, 2nd ed.; Elsevier: Amsterdam, The Netherlands, 2017; ISBN 978-0-12-811453-7.

27. MATLAB \& Simulink-MathWorks. Available online: https://www.mathworks.com/products/matlab.html (accessed on 1 December 2021).

28. Elangovan, K. Comparative Study on the Channel Estimation for OFDM System Using LMS, NLMS and RLS Algorithms. In Proceedings of the International Conference on Pattern Recognition, Informatics and Medical Engineering (PRIME-2012), Salem, India, 21-23 March 2012; pp. 359-363. [CrossRef]

29. Moshirian, S.; Ghadami, S.; Havaei, M. Blind Channel Equalization. arXiv 2012, arXiv:1208.2205.

30. Armstrong, J. OFDM for Optical Communications. J. Lightwave Technol. 2009, 27, 189-204. [CrossRef]

31. Smalley, D. Equalization Concepts: A Tutorial; Atlanta Regional Technology Center, Texas Instruments: Dallas, TX, USA, 1944; pp. 1-29.

32. Rai, A.; Kohli, A.K. Convergence Analysis of LMS Based Adaptive Filter. AIP Conf. Proc. 2010, 1324, 349-351. 
33. Haykin, S. Adaptive Filter Theory, 4th ed.; Prentice-Hall: Hoboken, NJ, USA, 2002.

34. Godard, D. Self-Recovering Equalization and Carrier Tracking in Two-Dimensional Data Communication Systems. IEEE Trans. Commun. 1980, 28, 1867-1875. [CrossRef]

35. Treichler, J.; Agee, B. A New Approach to Multipath Correction of Constant Modulus Signals. IEEE Trans. Acoust. Speech Signal Processing 1983, 31, 459-472. [CrossRef]

36. Fernandes, C.A.R.; Mota, J.C.M.; Favier, G. Decision Directed Algorithms for Blind Equalization Based on Constant Modulus Criteria. In Proceedings of the $20^{\circ}$ Colloquium on Signal and Image Processing, FRA, Novosibirsk, Russia, $20-24$ June 2005.

37. Johnson, R.; Schniter, P.; Endres, T.J.; Behm, J.D.; Brown, D.R.; Casas, R.A. Blind Equalization Using the Constant Modulus Criterion: A Review. Proc. IEEE 1998, 86, 1927-1950. [CrossRef]

38. Fatadin, I.; Ives, D.; Savory, S.J. Blind Equalization and Carrier Phase Recovery in a 16-QAM Optical Coherent System. J. Lightwave Technol. 2009, 27, 3042-3049. [CrossRef]

39. Tukey, J.W. Exploratory Data Analysis; SAGE Publications: London, UK, 1977; Volume 2.

40. Umbaugh, S.E. Computer Vision and Image Processing; Prentice-Hall: Bergen, NJ, USA, 1998.

41. Yazdi, H.S.; Homayouni, F. Impulsive Noise Suppression of Images Using Adaptive Median Filter. Int. J. Signal Processing Image Processing Pattern Recognit. 2010, 3, 1-12.

42. Fatadin, I. Estimation of BER from Error Vector Magnitude for Optical Coherent Systems. Photonics 2016, 3, 21. [CrossRef]

43. McKinley, M.D.; Remley, K.A.; Myslinski, M.; Kenney, J.S.; Schreurs, D.; Nauwelaers, B. EVM Calculation for Broadband Modulated Signals. In Proceedings of the 64th ARFTG Conference, Orlando, FL, USA, 2-3 December $2004 ;$ pp. 45-52.

44. 3GPP TS 38.104 5G; NR; Base Station (BS) Radio Transmission and Reception, v. 15.2 .0 (2018-7). Available online: https: //www.etsi.org/deliver/etsi_ts/138100_138199/138104/15.02.00_60/ts_138104v150200p.pdf (accessed on 15 December 2021). 